Article

\title{
Development and Performance Analysis of a New Self-Powered Magnetorheological Damper with Energy-Harvesting Capability
}

\author{
Lingbo $\mathrm{Li}^{1}$, Guoliang $\mathrm{Hu}^{2}, * \mathbb{C}$, Lifan $\mathrm{Yu}^{2}$ and Haonan $\mathrm{Qi}^{2}$ \\ 1 School of Mechanical Engineering, Southwest Jiaotong University, Chengdu 610031, China; \\ lilingbo@my.swjtu.edu.cn \\ 2 Key Laboratory of Conveyance and Equipment, Ministry of Education, East China Jiaotong University,

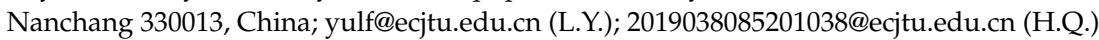 \\ * Correspondence: glhu@ecjtu.edu.cn
}

Citation: Li, L.; Hu, G.; Yu, L.; Qi, H. Development and Performance Analysis of a New Self-Powered Magnetorheological Damper with Energy-Harvesting Capability. Energies 2021, 14, 6166. https:// doi.org/10.3390/en14196166

Academic Editor:

Abdessattar Abdelkefi

Received: 29 July 2021

Accepted: 21 September 2021

Published: 27 September 2021

Publisher's Note: MDPI stays neutral with regard to jurisdictional claims in published maps and institutional affiliations.

Copyright: (c) 2021 by the authors. Licensee MDPI, Basel, Switzerland. This article is an open access article distributed under the terms and conditions of the Creative Commons Attribution (CC BY) license (https:// creativecommons.org/licenses/by/ $4.0 /)$

\begin{abstract}
Magnetorheological (MR) dampers, used as intelligent semi-active vibration control devices to achieve low energy consumption, fast response, controllability, and other capabilities are generally installed with a variety of sensors on their exterior to ensure that the damping force can be accurately controlled. However, external sensors are often affected by external complications that reduce the reliability of the damper, and the cost of powering the damper coils in remote locations where power is not available can be significantly increased. Based on these problems, a new self-powered MR damper scheme is proposed. The proposed MR damper has both energy-harvesting capabilities and damping controllability, and greatly improves the stability and application range of the device by converting vibration energy into electrical energy to supply the excitation coil. The MR damper can drive the piston rod in a linear reciprocating motion by external excitation, which converts mechanical energy into electrical energy via a DC brushless three-phase generator after conversion by a double-linkage mechanism. At the same time, the electrical energy generated by the generator is passed into the excitation coil to change the output damping force of the damper. Meanwhile, the damping performance and energy-harvesting efficiency of the new self-powered MR damper is experimentally tested. Experimental results show the damping force of the device reaches $1040 \mathrm{~N}$ when the applied current is $0.6 \mathrm{~A}$. The proposed self-powered MR damper has an instantaneous voltage amplitude of $1.782 \mathrm{~V}$ and a peak phase power of $4.428 \mathrm{~W}$ when the input excitation amplitude is $12.5 \mathrm{~mm}$ and the frequency is $3 \mathrm{~Hz}$.
\end{abstract}

Keywords: self-powered MR damper; double linkage; damping performance; vibration energy harvesting

\section{Introduction}

Since the 1980s, various types of damper have been used on a large scale for suspension systems for buildings, cable-stayed bridges, automobiles, and railroad vehicles [1]. Through decades of development, there are now three main types of dampers, namely, hydraulic dampers [2-4], electromagnetic dampers [5-7], and MR dampers [8-10]. Hydraulic dampers convert the reciprocating motion of hydraulic cylinder pistons into the rotational motion of hydraulic motors and generators through hydraulic fluid and store the energy in batteries for later use. The electromagnetic damper has no internal transmission structure, so it can directly use Faraday's electromagnetic induction principle to convert the kinetic energy of linear motion into electrical energy. This greatly reduces the efficiency loss caused by the transmission process. The magnetorheological effect of the magnetorheological fluid inside MR dampers occurs according to the action of a magnetic field, i.e., their rheological properties vary according to the strength of the external magnetic field and are highly controllable [11]. 
Researchers in different fields have done scientific investigations on these three types of dampers, and their research results are widely used in various fields. Wang et al. [12] proposed a hydraulic drive-based damper to achieve a recoverable power of $260 \mathrm{~W}$ at a frequency of $1 \mathrm{~Hz}$ and amplitude of $25 \mathrm{~mm}$, with sinusoidal excitation and an energy recovery efficiency of about $40 \%$. Zhang et al. [13] investigated the relationship between the increase in oil temperature and the change in damping force inside the damper and verified it experimentally. Xu et al. [14] proposed a hydroelectric damper with a slidevalve hydraulic rectifier mechanism, where the liquid passes through the hydraulic circuit, driving the hydraulic motor in a constant direction of rotation. The designed damping force control method can achieve active control, and the average output power of the damper is $400 \mathrm{~W}$ to $800 \mathrm{~W}$ under experimental conditions. Maravandi et al. [15] proposed a spatial sixlinkage feedthrough energy damper that converts linear motion into rotary motion using a spatial six-linkage mechanism, which was tested at an average mechanical efficiency of $56 \%$. Yu et al. [16] designed a ball screw type electromagnetic damper with a maximum line voltage output of $17.5 \mathrm{~V}$, for a sinusoidal excitation with an amplitude of $5 \mathrm{~mm}$. The helical gear electromagnetic damper designed by Waleed et al. [17] uses a helical gear helical drive, then rectifies the current with a motion rectification mechanism composed of a one-way clutch, and finally drives the motor to rotate around in one direction; the results showed that its average energy recovery efficiency is $40 \%$. Zhao et al. [18] proposed a nonlinear damper for variable-damping rotor systems that uses a smart material shear-thickened fluid (STF) whose viscosity and damping increase significantly with increasing shear rate. Kim et al. [19] proposed an MR damper whose damping force can be adjusted by the shape of the housing. Mohsen et al. [20] proposed a molecular model of a miniature MR damper using a dissipative particle dynamics approach to study the effect of magneto-fluid properties on the damping force.

Based on the rapid development of new intelligent materials, magnetorheological fluid, as a new intelligent material, has the advantages of continuously controllable damping force, short response time, simple structure, low energy consumption, and wide adjustable range. It can change instantaneously from a flowing Newtonian fluid to a solid-like state under the action of an external magnetic field, and a flowing state in the absence of a magnetic field. Therefore, MR dampers with magnetorheological fluid as the working medium have been intensively studied by scholars from various countries. According to the working mode, MR dampers can be divided into three types: shear type, flow type, and squeeze type. Du et al. [21] designed an MR damper, a device that avoids rapid increases in MR fluid temperature during operation by adding an aluminum foil bubble insulation with low thermal conductivity to the cavity. Yazid et al. [22] proposed an MR damper consisting of a combination of shear and squeeze modes, and the damping characteristics were experimentally tested for shear mode, squeeze mode, and mixed mode by simulating the magnetic field generated by the excitation coil of the MR damper through finite element analysis. Robinson et al. [23] designed an MR damper with a porous bypass valve and evaluated the effect of the choice of porous media on the maximum controllable damping force and damping coefficient. Kim et al. [24] designed and fabricated an MR damper with a folded-flow pattern, and experimentally demonstrated that the proposed MR damper has better damping controllability than conventional dampers.

Despite the advantages of MR dampers, if better damping is required in practice, we need to install auxiliary equipment such as external power supplies, high-precision feedback sensors, and controllers in their external devices or systems. If we want to apply the damper to large buildings or rail equipment and other harsh and complex structures, this auxiliary equipment will make the failure rate and maintenance costs of the damper higher, while reducing their practicality and reliability. In response to these problems, scholars have proposed and developed various forms of functionally integrated MR damper. An MR damper with embedded piezoelectric force sensors was proposed by Or et al. [25] and applied in a structural vibration control system. This integrated MR damper obtained a wide frequency response range and high charge force coefficient 
with good controllable damping force performance under sinusoidal and ramp excitations with frequencies of $0.2-10 \mathrm{~Hz}$, and amplitudes of 200-500 N. Lam et al. [26] proposed an MR damper with force and displacement sensing by incorporating a piezoelectric force transducer and a linear differential transformer (LVDT) into a conventional MR damper, and experimentally demonstrated that their LVDT is also capable of accurately monitoring displacement changes in vibration; the results reflect that the structure is capable of realizing real-time closed-loop feedback control of vibration systems. Hu et al. [27] designed a displacement differential self-induced MR damper, which was analyzed by experimental tests, and the damper can both control the output of the damping force better and obtain an induced voltage proportional to the relative displacement of the piston rod; the induced voltage can reach $0.9 \mathrm{~V}$.

In addition, problems with the installation of external equipment can occur on some special occasions, such as in remote areas, mining areas, and other areas prone to power outages; MR dampers without external energy supply equipment will have limited practical application. Due to the lack of power supply infrastructure such as cables, power stations, and power grids, the output efficiency of wind and solar hybrid power generation in some remote plateau mountainous areas will be affected by light intensity, dust, rain, wind speed, altitude, sunshine time, temperature changes, transmission systems, and power generation. In order to make the MR damper to be used in this complex and special environment, it must be ensured that the damper can obtain a stable energy supply, and that the power will be cut off in unexpected situations-it can still give full play to its damping function afterwards. Based on the comprehensive consideration of these factors, self-power after collection of the existing vibration energy from the work of the MR damper has become a good energy supply method. The MR damper works in a vibrating environment, and its damping method works by solidifying external vibration energy through MR fluids, which emits frictional heat generated by the corresponding structural surface of the dampers, ultimately leading to a waste of energy. If the vibration energy can be converted into electrical energy to supply the MR damper, various problems caused by its external equipment can be solved, and the vibration energy will be recovered at the same time, which improves the practicality and energy saving of the MR damper.

At this stage, many researchers have also conducted research related to vibration energy harvesting of MR dampers. Dong et al. [28] designed an axial flux permanent magnet energy harvesting damper, which uses a disk structure to convert the linear motion of the vehicle suspension into rotational motion through a reverse ball screw to improve energy harvesting efficiency. Sapinski et al. [29] designed an energy-harvesting MR damper with an integrated electromagnetic induction device, which arranged the energy-harvesting structure linearly with the damper structure, and solved the problem of damper power supply by harvesting external vibration energy; after the electronic control system, it was able to supply the collected electrical energy directly to the MR damper. Guan et al. [30] developed an MR damper with a double outlet rod for self-power supply. This selfcollecting structure uses the combination of a ball screw sub and a rotating generator to convert vibration energy into electrical energy, to power the excitation coil through its mechanical structure. It has been proved that this structure can carry out this self-collecting function and achieve good controllability of damping force. Yu et al. [31] proposed an integrated wireless sensor and energy-harvesting MR damper, which drives the rotational motion of the fan blades by the kinetic energy of the internal fluid, and drives a rotating generator to generate electrical energy, which is simultaneously powered to the internal wireless sensor.

Although researchers have done a lot of research related to vibration energy-harvesting MR dampers, the existing vibration energy-harvesting techniques for MR dampers still face problems such as low output power, complex structures, and high cost. To solve these problems, an efficient self-powered MR damper is proposed in this paper, which combines a double-linkage mechanical conventional mechanism with a conventional linear double-output rod MR damper. This damper adopts a closed upper and lower sleeve 
structure. Compared to existing studies, this new self-powered MR damper based on a double-linkage mechanism has high energy conversion efficiency in addition to its simple structure and low manufacturing cost.

\section{Principle and Structure of Self-Powered MR Dampers}

The conventional dual-output rod-type MR damper generally consists of a dual-output piston rod, coil-winding frame, cylinder body, excitation coil, and other components. When the damper is working, the piston rod moves back and forth relative to the damper cylinder due to external vibration, and the MR fluid is squeezed to flow back and forth in the cylinder. When the excitation coil is energized, the magnetorheological effect will occur in the magnetorheological fluid in the flow channel inside the device, generating shear stress and impeding the relative motion of the piston head.

A new self-powered MR damper based on a double-linkage mechanism vibration energy-harvesting device and MR damper is proposed, as shown in Figure 1. The threedimensional model of the self-powered MR damper is shown in Figure 1a. The device consists of a ring, dual-output piston rod, excitation coil, piston head, sealing ring, upper connector, upper rotating plate, spatial link, ball socket, ball joint, lower rotating plate, lower connector, planetary gearbox, generator, and other components. The structural parameter diagram of the self-powered MR damper is shown in Figure $1 \mathrm{~b}$. The vibration energy-harvesting unit of the device includes a DC brushless three-phase generator with a planetary gearbox and a double-linkage mechanism. The bottom of the double-output piston rod in the damper is connected to the double-linkage motion conversion mechanism through the upper connection, and the other section of the machine is connected to the input shaft of the DC brushless three-phase motor with planetary gearbox through the lower connection. When the piston rod is induced to move back and forth, the upper and lower fixed rings are fixed on the upper and lower sleeves and cannot rotate. Under the action of the connecting rod, the lower circular plate and the lower bearing sleeve rotate. The double-linkage mechanism converts the up-and-down linear motion into the rotary motion of the generator input shaft. The working-principle diagram of the transmission component of the device is shown in Figure 1c. The instantaneous voltage generated by the generator is proportional to the amplitude of the vibration input excitation. As the input excitation to the piston rod increases, the current flowing into the excitation coil increases, and the greater the damping force provided. Therefore, the self-powered MR damper can perform adaptive damping adjustment without any external equipment for power supply, which reduces the impact of various exterior disturbances on the performance of the device and improves the practicality and reliability of the device. The main dimensional parameters of the proposed self-powered MR damper are shown in Table 1.

Table 1. Parameters of the self-powered MR damper.

\begin{tabular}{ccccc}
\hline Design Parameter & Values & Design Parameter & Values \\
\hline Radius of the piston head bore $r_{1} / \mathrm{mm}$ & 5 & Thickness of the damping channel $h / \mathrm{mm}$ & 1 \\
Radius of the piston rod $r_{2} / \mathrm{mm}$ & 8 & Length of the piston head $L / \mathrm{mm}$ & 45 \\
Radius of the piston head $r_{3} / \mathrm{mm}$ & 20.5 & Length of the yoke of piston head flanks $l / \mathrm{mm}$ & 6 \\
Radius of the cylinder body $r_{4} / \mathrm{mm}$ & 27.5 & Width of the winding groove $w / \mathrm{mm}$ & 33 \\
Length of the cylinder $L_{\mathrm{d}} / \mathrm{mm}$ & 135 & Depth of the winding groove $t / \mathrm{mm}$ & 7.5 \\
Length of the piston head $h_{\mathrm{d}} / \mathrm{mm}$ & 6 & Turns of coil $N$ & 485 \\
\hline
\end{tabular}




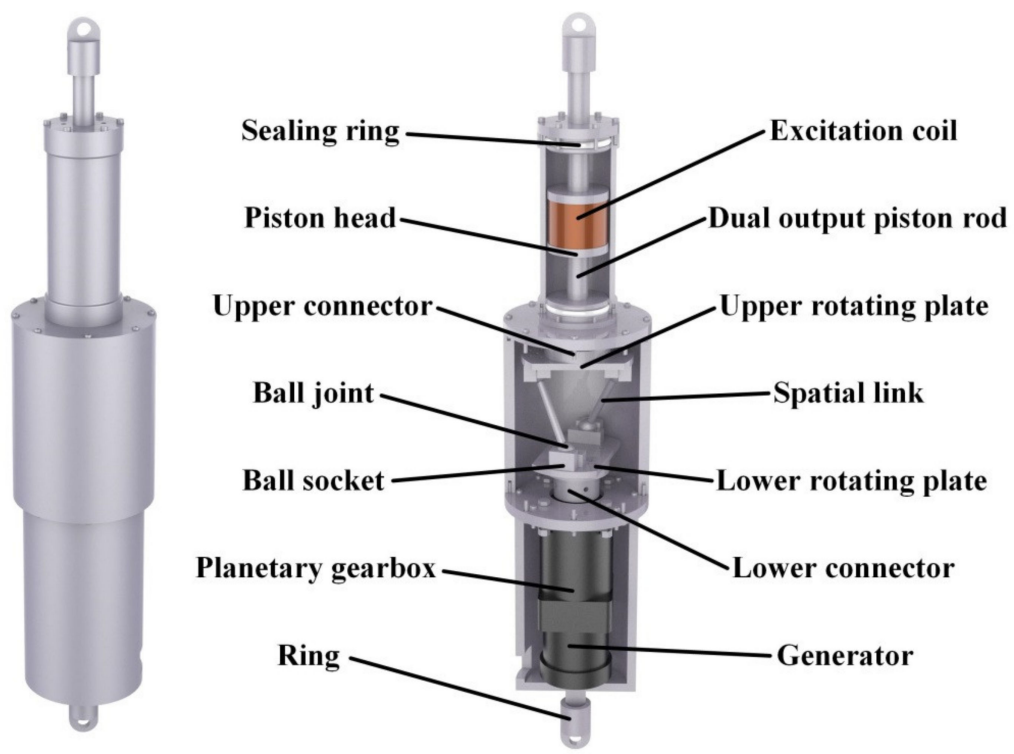

(a)

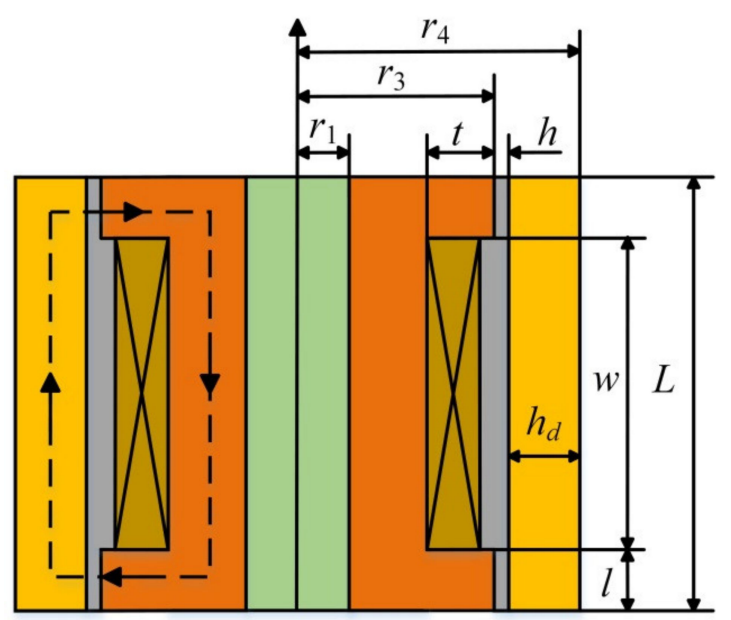

(b)
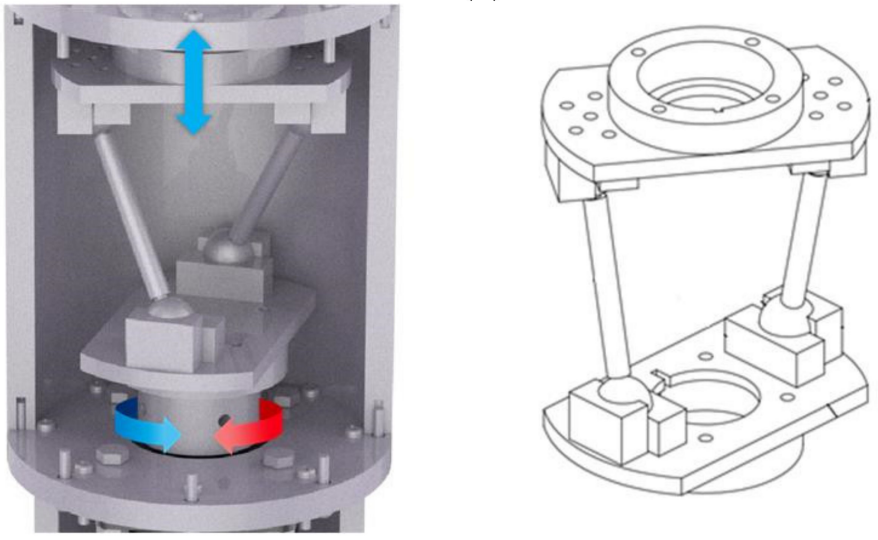

(c)

Figure 1. Structural diagram of the proposed self-powered MR damper. (a) Three-dimensional view of a self-powered MR damper. (b) Structural parameters of the self-powered MR damper. (c) Working-principle diagram of the transmission component of the device. 


\section{Modeling and Analysis of a Self-Powered MR Damper}

The dynamic response process of the self-powered MR damper is a coupled response process of electricity, magnetism, and mechanics. The process can be described as follows: external excitation drives the piston rod in a linear motion, which is converted into a rotational motion of the generator input shaft by the double-linkage mechanism. The electrical energy output from the generator is supplied to the excitation coil, which generates a magnetic field with current passing through it and converts the electrical energy into magnetic energy. Magnetorheological fluid in the damper changes its shear yield stress under the action of a magnetic field.

\subsection{Kinematic Analysis of Double-Linkage Mechanisms}

To obtain the kinematic relationship of the double-linkage mechanism during transmission, this subsection provides a kinematic analysis of the double-linkage mechanism. For the sake of understanding and elaboration, this section only analyzes cases where the upper and lower rotating plates are close to each other, the upper rotating plate does not move, and the lower rotating plate rotates under the drive of the connecting rod. Therefore, the spatial coordinate system is established with the upper crossbar as the reference, as shown in Figure 2. Based on the geometric relationship between the two crossbars and the two connecting rods in Figure 2, an equation describing the motion between the lower crossbar and the diagonal rod can be obtained:

$$
l^{2}=s^{2}+a^{2}
$$

where $l$ is the connecting rod length, $s$ is the spacing between the upper and lower crossbars, and $a$ is the projection of the connecting rod in the XOY plane.

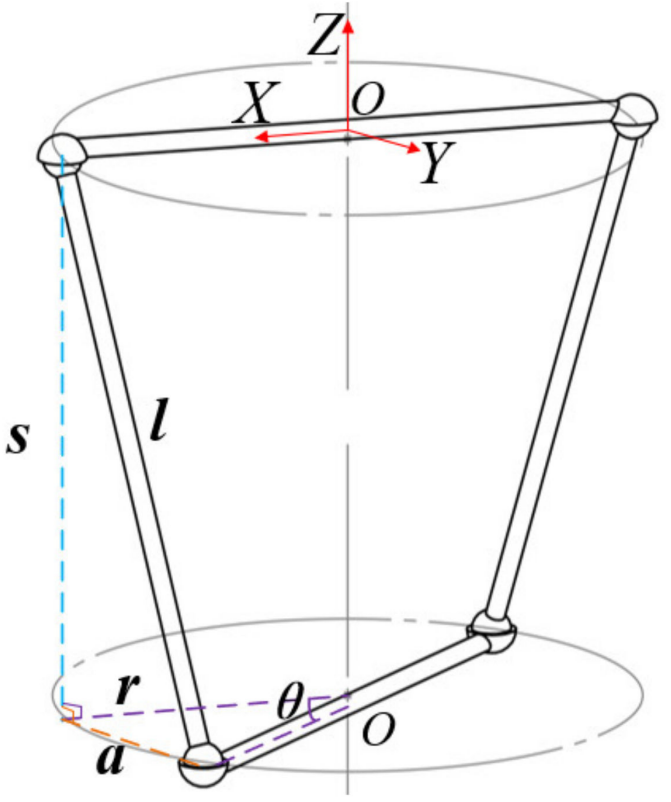

Figure 2. Double-linkage mechanism space geometry relationship diagram.

The projection of the connecting rod in the XOY plane can be decomposed along the $\mathrm{X}$ and $\mathrm{Y}$ axes, as shown in Figure 3. 


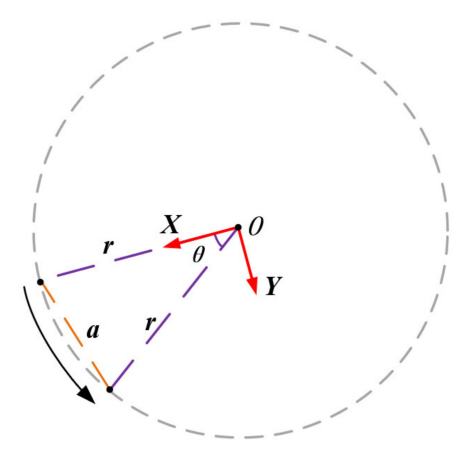

Figure 3. Projection of the double linkage on the XOY plane.

From the geometric relationship in the figure, it can be seen that:

$$
\begin{gathered}
a^{2}=a_{\mathrm{x}}^{2}+a_{\mathrm{y}}^{2} \\
\left\{\begin{array}{c}
a_{\mathrm{x}}=(1-\cos \theta) r \\
a_{\mathrm{y}}=\sin \theta r
\end{array}\right.
\end{gathered}
$$

where $a_{\mathrm{x}}$ is the length of the projection $a$ decomposed along the $X$-axis, $a_{\mathrm{y}}$ is the length of the projection $a$ decomposed along the $Y$-axis, $\theta$ is the rotation angle, and $r$ is the rotation radius of the crossbar, the size of which is half of the length of the crossbar. By substituting (3) into (2), the results can be obtained:

$$
a^{2}=2(1-\cos \theta) r^{2}
$$

Substituting Equation (4) into Equation (1), the relationship between the crossbar spacing $s$ and the connecting rod length $l$, the crossbar rotation radius $r$, and the rotation angle $\theta$ can be obtained as follows:

$$
s=\sqrt{l^{2}-2(1-\cos \theta) r^{2}}
$$

Through Equation (5), combined with the conclusions of the above crossbar length and connecting rod length values and the travel requirement of the damper, and considering the connecting rod diameter and the drive shaft diameter, as well as manufacturing limitations, the nonlinear relationship curve between the rotation angle $\theta$ and the crossbar spacing $s$ is simulated, as shown in Figure 4.

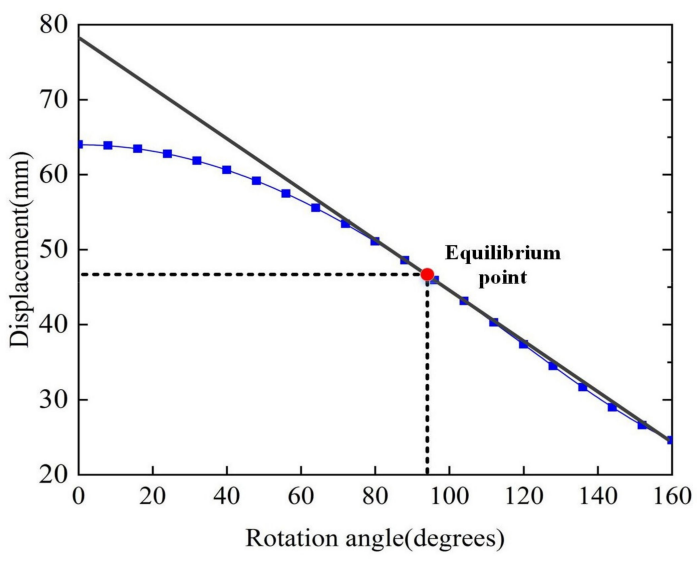

Figure 4. Nonlinear relationship between rotation angle $\theta$ and displacement $s$, and linear relationship at the equilibrium point. 
To avoid collisions between the connecting rod and the drive shaft, the motion translation range of the double-linkage drive mechanism was designed to convert $34 \mathrm{~mm}$ translational motion into $142^{\circ}$ rotational motion. Therefore, the static equilibrium points $s_{0}=47 \mathrm{~mm}$ and $\theta_{0}=94^{\circ}$ are taken. Because the double-linkage mechanism is used as a motion converter from linear motion to rotational motion, the relationship between the translational and rotational velocities between the two crossbars must be obtained. Equation (5) is derived from time on both sides:

$$
\dot{s}=-\frac{\sin \theta r^{2}}{\sqrt{l^{2}-2(1-\cos \theta) r^{2}}} \dot{\theta}
$$

The relative translational motion $\Delta s$ and $\Delta \theta$ relative rotational motion can be expressed as:

$$
\begin{aligned}
\Delta s & =s-s_{0} \\
\Delta \theta & =\theta-\theta_{0}
\end{aligned}
$$

where $s_{0}$ and $\theta_{0}$ denote the static equilibrium points of $s$ and $\theta$. Substituting Equations (7) and (8) into Equation (5), the linear relationship approximation can be written as:

$$
\dot{s}=m \dot{\theta}
$$

where $m$ is the linear slope of the nonlinear relationship between the translational and rotational velocities.

Since the transmission of the two rods is basically non-linear, in order to avoid the buckling phenomenon that may occur, we choose the material of the connecting rod to be 45 steel, and the length of the connecting rod to be $64 \mathrm{~mm}$, and the minimum technical width to be $6 \mathrm{~mm}$.

\subsection{Dynamics Analysis of a Self-Powered MR Damper}

The total damping force $F$ of the self-powered MR damper is mainly composed of the damping force $F_{\mathrm{E}}$ generated by the vibration energy-harvesting device and the magnetorheological damping force $F_{\mathrm{MR}}$, which can be described as:

$$
F=F_{\mathrm{E}}+F_{\mathrm{MR}}
$$

As shown in Figure 5, external forces act on the device. The new self-powered MR damping force can be defined by the Lagrangian equation, which is expressed as:

$$
F_{\mathrm{E}}=\frac{d}{d t}\left(\frac{\partial T}{\partial \dot{x}}\right)-\left(\frac{\partial T}{\partial x}\right)+\frac{\partial D}{\partial \dot{x}}
$$

where $x$ is the displacement, $D$ is the system dissipation function, and $T$ is the kinetic energy of the system, which is given by:

$$
T=\frac{1}{2} m_{\text {cout }} \dot{x}^{2}+\frac{1}{2} m_{\mathrm{z}} \dot{x}^{2}+\frac{1}{2} J_{\mathrm{t}} \dot{\theta}^{2}+\frac{1}{2} J_{\mathrm{z}} \dot{\theta}^{2}+\frac{1}{2} J_{\mathrm{f}} \dot{\theta}^{2}+\frac{1}{2} J_{\mathrm{pg}} \dot{\theta}^{2}+\frac{1}{2} J_{\mathrm{g}}(i \dot{\theta})^{2}
$$

where $\dot{x}$ is the speed of the dual-output piston rod, $i$ is the transmission ratio of the planetary gearbox, $m_{\text {cout }}$ is the mass of the dual-output piston rod, $m_{\mathrm{z}}$ is the mass of the other components, $J_{\mathrm{t}}, J_{\mathrm{z}}, J_{\mathrm{f}}, J_{\mathrm{pg}}$, and $J_{\mathrm{g}}$ are the amounts of inertia of the double linkage, upper connector, lower connector, planetary gearbox, and generator, respectively. Substituting the relational equations for linear and rotational motion, $T$ can be expressed as:

$$
T=\frac{1}{2}\left(m_{\text {cout }}+m_{\mathrm{z}}+\frac{J_{\mathrm{t}}+J_{\mathrm{z}}+J_{\mathrm{f}}+J_{\mathrm{pg}}+i^{2} J_{\mathrm{g}}}{m^{2}}\right) \dot{x}^{2}
$$




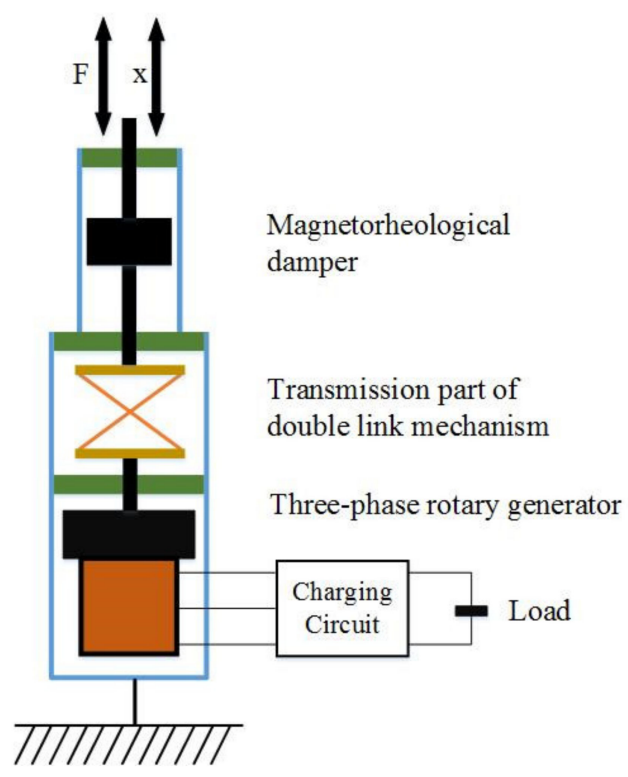

Figure 5. Schematic diagram of the dynamics model of a self-powered MR damper.

The damping effect $D$ is given by the following equation:

$$
D=\frac{1}{2} C_{\mathrm{L}} \dot{x}^{2}
$$

The rotational damping coefficient and linear damping coefficient of the vibration energy-harvesting device can be expressed respectively as:

$$
\begin{gathered}
C_{\mathrm{R}}=\frac{1.5 k_{\mathrm{e}}^{2}}{R_{\mathrm{e}}+R_{\mathrm{i}}} \\
C_{\mathrm{L}}=\frac{1.5 i^{2} k_{\mathrm{e}}^{2}}{\eta_{\mathrm{j}} \eta_{\mathrm{pg}} \eta_{\mathrm{g}}\left(R_{\mathrm{e}}+R_{\mathrm{i}}\right) m^{2}}
\end{gathered}
$$

where $k_{\mathrm{e}}$ is the back electromotive voltage constant of the generator, $R_{\mathrm{e}}$ is the external resistance of the circuit, $R_{\mathrm{i}}$ is the internal resistance of the generator, $\eta_{\mathrm{j}}$ is the mechanical efficiency of the double-linkage mechanism, $\eta_{\mathrm{pg}}$ is the mechanical efficiency of the planetary gearbox, and $\eta_{\mathrm{g}}$ is the mechanical efficiency of the generator.

Since most of the DC brushless motors have a three-phase winding with a star connection, the dynamic model of the DC brushless generator is shown in Figure 6.

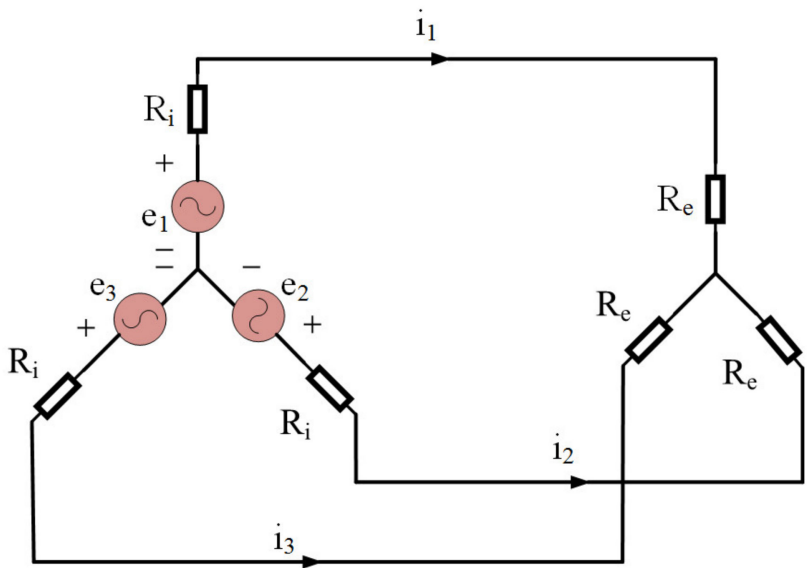

Figure 6. DC brushless motor connected to the simplified charging circuit. 
Therefore, substituting Equations (13) and (14) into Equation (11):

$$
F_{\mathrm{E}}=\left(m_{\text {cout }}+m_{\mathrm{z}}+\frac{J_{\mathrm{t}}+J_{\mathrm{z}}+J_{\mathrm{f}}+J_{\mathrm{pg}}+\dot{i}^{2} J_{\mathrm{g}}}{m^{2}}\right) \ddot{x}+C_{\mathrm{L}} \dot{x}
$$

The inertia coefficient represents the effect of acceleration on its damping force, and the equivalent inertial mass of the self-powered MR damper can be expressed as:

$$
m_{\mathrm{eq}}=m_{\text {cout }}+m_{\mathrm{z}}+\frac{J_{\mathrm{t}}+J_{\mathrm{z}}+J_{\mathrm{f}}+J_{\mathrm{pg}}+i^{2} J_{\mathrm{g}}}{m^{2}}
$$

The self-powered MR damper designed in this paper belongs to the shear valve mode of operation; when the piston rod is subjected to external excitation, the magnetorheological fluid in the damping chamber has both shear flow and differential pressure flow, and its output magnetorheological damping force can be understood as consisting of the damping force generated in the shear mode and the valve mode-it can be obtained as:

$$
F_{\mathrm{MR}}=F_{\mathrm{s}}+F_{\mathrm{p}}
$$

where $F_{\mathrm{s}}$ is the damping force generated by the device in shear mode and $F_{\mathrm{p}}$ is the damping force generated by the device in valve mode. From the Bingham pseudo-static model, it can be seen that the damping force generated by the MR damper is divided into two parts: viscous damping force derived from its viscosity and magneto-damping force derived from its magnetic field, regardless of the operating mode of the MR damper. The total output damping force can be obtained as:

$$
F_{\mathrm{n}}=F_{\eta}+F_{\tau}
$$

where $F_{\eta}$ is the viscous damping force and $F_{\tau}$ is the magnetically induced damping force. The viscous damping force in shear mode can be expressed as:

$$
F_{\mathrm{s} \eta}=\frac{2 \pi r_{3} L \eta}{h} \dot{x}
$$

The magnetically induced damping force in shear mode can be obtained as:

$$
F_{\mathrm{s} \tau}=4 \pi r_{3} l \tau_{\mathrm{y}} \operatorname{sgn}(\dot{x})
$$

For the shear flow of magnetorheological fluid in shear mode, the resulting damping force is the sum of Equations (21) and (22); it can be concluded that:

$$
F_{\mathrm{s}}=\frac{2 \pi r_{3} L \eta}{h} \dot{x}+4 \pi r_{3} l \tau_{\mathrm{y}} \operatorname{sgn}(\dot{x})
$$

The viscous damping force in valve mode can be expressed as:

$$
F_{\mathrm{p \eta}}=\frac{6 \eta L A_{\mathrm{p}}^{2}}{\pi r_{3} h^{3}} \dot{x}
$$

The magnetically induced damping force in valve mode can be expressed as:

$$
F_{\mathrm{p} \tau}=\frac{2 c l}{h} A_{\mathrm{p}} \tau_{\mathrm{y}} \operatorname{sgn}(\dot{x})
$$

For the differential pressure flow of magnetorheological fluid in valve mode, the resulting damping force is the sum of Equations (24) and (25); it can be concluded that:

$$
F_{\mathrm{p}}=\frac{6 \eta L A_{\mathrm{p}}^{2}}{\pi r_{3} h^{3}} \dot{x}+\frac{2 c l}{h} A_{\mathrm{p}} \tau_{\mathrm{y}} \operatorname{sgn}(\dot{x})
$$


Substituting Equations (23) and (26) into Equation (19) yields:

$$
F_{\mathrm{MR}}=\left(\frac{2 \pi r_{3} L \eta}{h}+\frac{6 \eta L A_{\mathrm{p}}^{2}}{\pi r_{3} h^{3}}\right) \dot{x}+\left(4 \pi r_{3} l+\frac{2 c l}{h} A_{\mathrm{p}}\right) \tau_{\mathrm{y}} \operatorname{sgn}(\dot{x})
$$

where $\eta$ is the zero-field viscosity of the magnetorheological fluid, $A_{\mathrm{p}}$ is the effective area of the piston head, $c$ is the correction factor, and $\tau_{\mathrm{y}}$ is the yield stress of the magnetorheological fluid in the flanking damping channel; the effective area of the piston head $A_{\mathrm{p}}$ can be expressed as:

$$
A_{\mathrm{p}}=\pi\left(r_{3}^{2}-r_{2}^{2}\right)
$$

To evaluate the adjustable performance of the magnetorheological damping output damping force, the ratio of magneto and viscous damping force is commonly used as the damping adjustable factor $\beta$ of the damper; it can be seen that:

$$
\beta=\frac{F_{\tau}}{F_{\eta}}=\frac{F_{\mathrm{s} \tau}+F_{\mathrm{p} \tau}}{F_{\mathrm{s} \eta}+F_{\mathrm{p} \eta}}
$$

Substituting Equations (17) and (27) into Equation (10) yields:

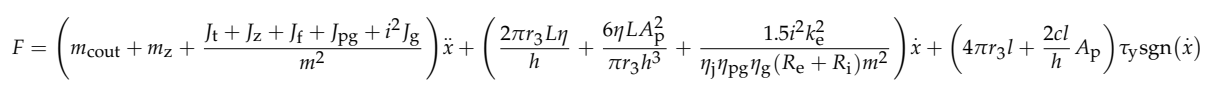

\subsection{Simulation Analysis of the MR Damper}

The structure of the proposed self-powered MR damper was simulated by the finite element method using ANSYS software for static electromagnetic field analysis. The MRFJ25T-type MR fluid fabricated by Chongqing Institute of Materials Research in China was used. The $\tau-B$ curve and B-H curve of this type of MR fluid are shown in Figure 7a,b, respectively.

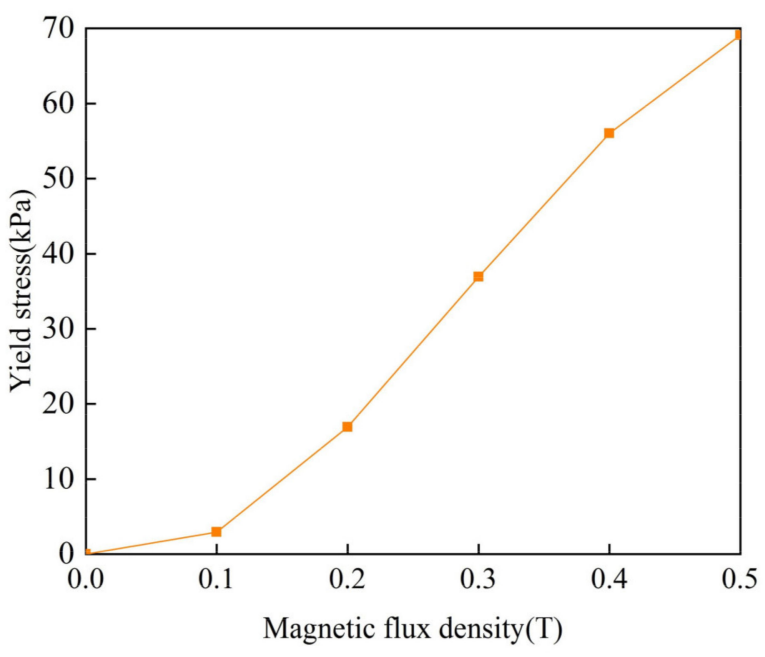

(a)

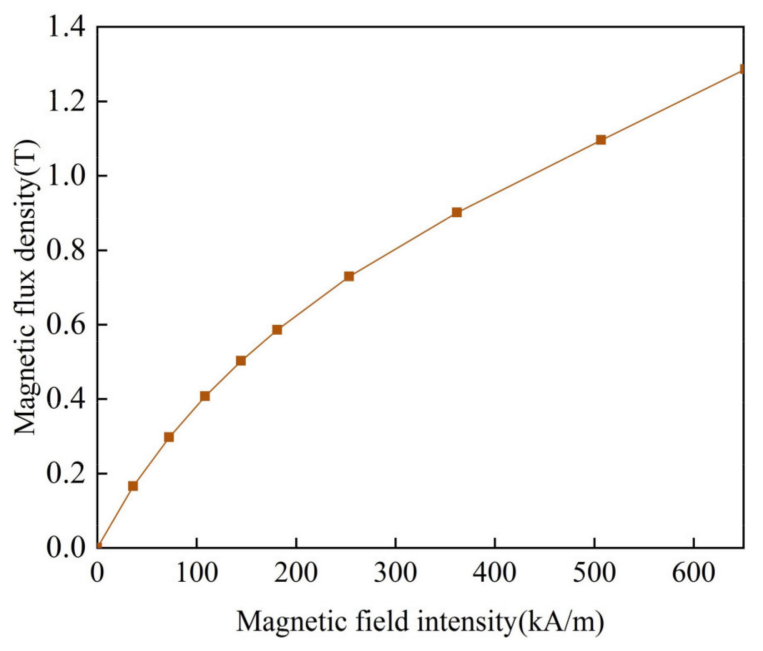

(b)

Figure 7. Performance of magnetorheological fluid. (a) $\tau$-B curve. (b) B-H curve.

Then, the relationship between the shear yield stress $\tau_{\mathrm{y}}$ of MR fluid and the induction strength $B$ of the applied magnetic field was fitted using MATLAB as:

$$
\tau_{\mathrm{y}}=b_{0} \times B^{3}+b_{1} \times B^{2}+b_{2} \times B+b_{3}
$$

where $b_{0}, b_{1}, b_{2}$, and $\mathrm{b}_{3}$ are polynomial coefficients, respectively, where $b_{0}=-2452 \mathrm{kPa} / \mathrm{T}^{3}$, $b_{1}=5892 \mathrm{kPa} / \mathrm{T}^{3}, b_{2}=11,250 \mathrm{kPa} / \mathrm{T}^{3}$, and $b_{3}=0$. 
Applying current density to the excitation coil region, the electromagnetic field inside the designed damper when the excitation current is given as $1 \mathrm{~A}$ is shown in Figure 8. From the figure, it can be seen that the damping channels in the device can be divided into sections S1, S2 and S3, where the dense magnetic lines in S1 and S3 sections are the effective damping channels. Figure 8a shows the magnetic flux distribution inside the designed damper when the excitation current is given as $1 \mathrm{~A}$. The magnetic flux lines pass through the piston head and cylinder to form a closed circuit, and their direction is in accordance with the expectation of the magnetic circuit theory analysis. The magnetic flux lines are mostly perpendicular to the effective damping channels S1 and S3. Figure 8b shows the magnetic flux density contour at the applied current of $1 \mathrm{~A}$. The magnetic field is not uniformly distributed in the damping channel, and the magnetic flux density is larger at the two effective damping channels, while it tends to be almost zero at the $\mathrm{S}_{2}$ section, which is consistent with the distribution of magnetic flux lines in Figure 8a.

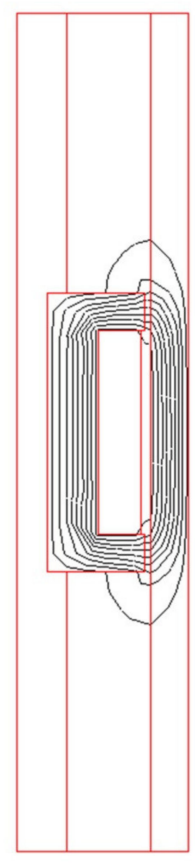

(a)

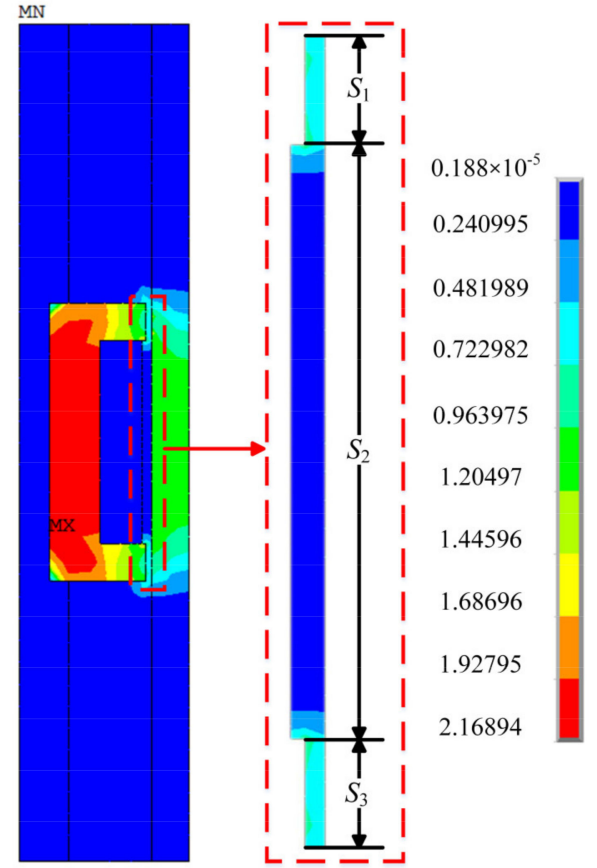

(b)

Figure 8. Magnetic field distribution inside a self-powered MR damper. (a) Magnetic line distribution. (b) Magnetic induction intensity cloud map.

The average magnetic flux density at the effective damping channel in the device can be expressed as:

$$
\bar{B}=\frac{\int B d a}{\int d a}
$$

where $B$ is the magnetic flux density at each point of $S_{1}$ and $S_{3}$, respectively, and $a$ is the unit length of $S_{1}$ and $S_{3}$, respectively. The magnetic flux density at $S_{1}$ and $S_{3}$ of the effective damping channel at each current is integrated and divided by the channel length, and the average magnetic flux density variation curve with current is shown in Figure 9. As can be seen from Figure 9, the average magnetic flux density at the effective damping channel tends to increase with increases in the excitation current, and the average magnetic flux density reaches $0.597 \mathrm{~T}$ when the current is $1.4 \mathrm{~A}$. It is also found that after the excitation current exceeds $1 \mathrm{~A}$, the average magnetic flux density tends to increase slowly with the current, indicating that the designed self-powered MR damper is approaching magnetic saturation. 


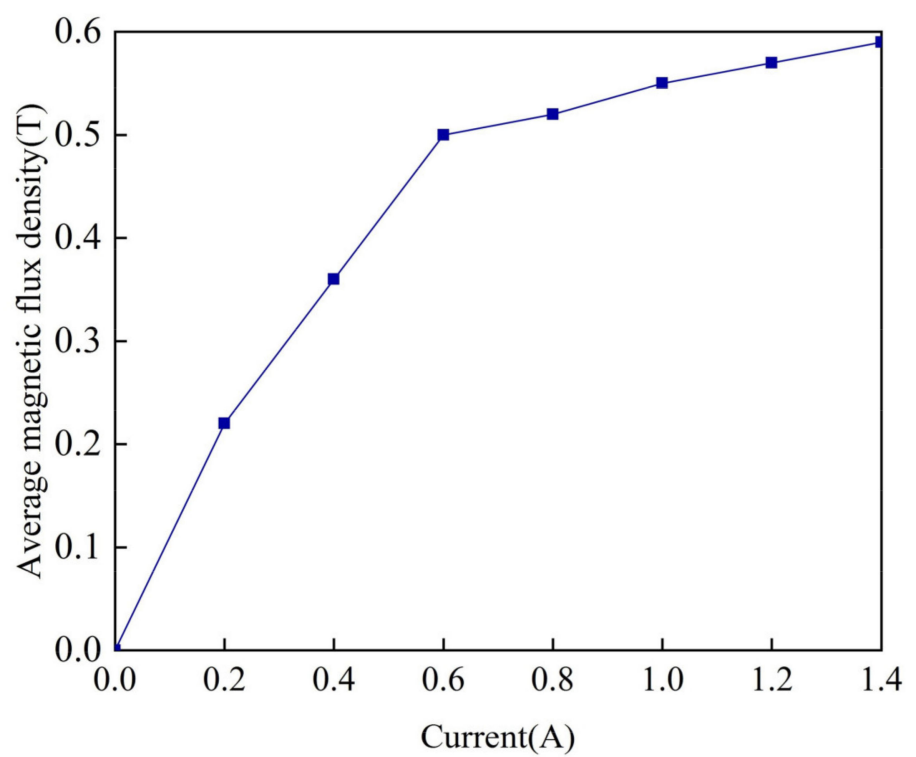

Figure 9. Variation curve of average magnetic flux density with current.

From Equation (16), it can be seen that the linear damping coefficient of the system is inversely related to the external load resistance when the mechanical efficiency is constant. The linear damping coefficient of the self-powered MR damper can be controlled by changing the external load resistance. Meanwhile, the mechanical efficiency parameters of each transmission component in the damper are estimated as follows: the mechanical efficiency of the double-linkage mechanism $\eta_{\mathrm{j}}$, the mechanical efficiency of the planetary gearbox $\eta_{\mathrm{pg}}$, and the mechanical efficiency of the generator $\eta_{\mathrm{g}}$ are $0.92,0.90$, and 0.90 , respectively. The total mechanical efficiency of the system is thus 0.75 . The parameters of the prototype of the self-powered MR damper are given in Table 2.

Table 2. Parameters of the prototype of the self-powered MR damper.

\begin{tabular}{|c|c|c|c|}
\hline Parameter & Values & Design Parameter & Values \\
\hline Inertia of double linkage $J_{\mathrm{t}} / \mathrm{kg} \cdot \mathrm{mm}^{2}$ & 31.131 & Mass of other parts $m_{\mathrm{z}} / \mathrm{kg}$ & 0.40 \\
\hline Inertia of upper connector $J_{\mathrm{z}} / \mathrm{kg} \cdot \mathrm{mm}^{2}$ & 130.05 & Zero field viscosity of magnetorheological fluid $\eta$ & 0.80 \\
\hline Inertia of lower connector $J_{\mathrm{f}} / \mathrm{kg} \cdot \mathrm{mm}^{2}$ & 137.63 & Correction factor $c$ & 3 \\
\hline Inertia of planetary gearbox $J_{\mathrm{pg}} / \mathrm{kg} \cdot \mathrm{cm}^{2}$ & 0.15 & Back electromotive voltage constant $k_{\mathrm{e}} / \mathrm{V} \cdot \mathrm{s} / \mathrm{rad}$ & 0.0456 \\
\hline Inertia of generator $J_{\mathrm{g}} / \mathrm{mm}$ & 0.29 & $\begin{array}{l}\text { The slope of nonlinear relationship between } \\
\text { translational and rotational velocities } \mathrm{m} / \mathrm{mm}\end{array}$ & -19.1 \\
\hline Mass of dual-output piston rod $m_{\text {Cout }} / \mathrm{kg}$ & 0.58 & Internal resistor of generator $r / \Omega$ & 0.45 \\
\hline
\end{tabular}

When the damper is subjected to a sinusoidal excitation with an amplitude of $10 \mathrm{~mm}$ and frequency of $1 \mathrm{~Hz}$, Figure 10 shows the variation curve of the output damping force with displacement for different excitation currents. As can be seen from Figure 10, the output damping force varies greatly with displacement, and the damping force -displacement curve has a fuller "back" shape, and is symmetrically distributed around the relative equilibrium position. Comparing the force-displacement curves at each current, it can be seen that the output damping force of the damper will increase with increases in the excitation current. The main reason for this is that as the applied current increases, the magnetic flux density of the damping channel becomes larger. Also, as the magnetic field is enhanced, the magnetically induced damping force increases, which results in a larger output damping force. 


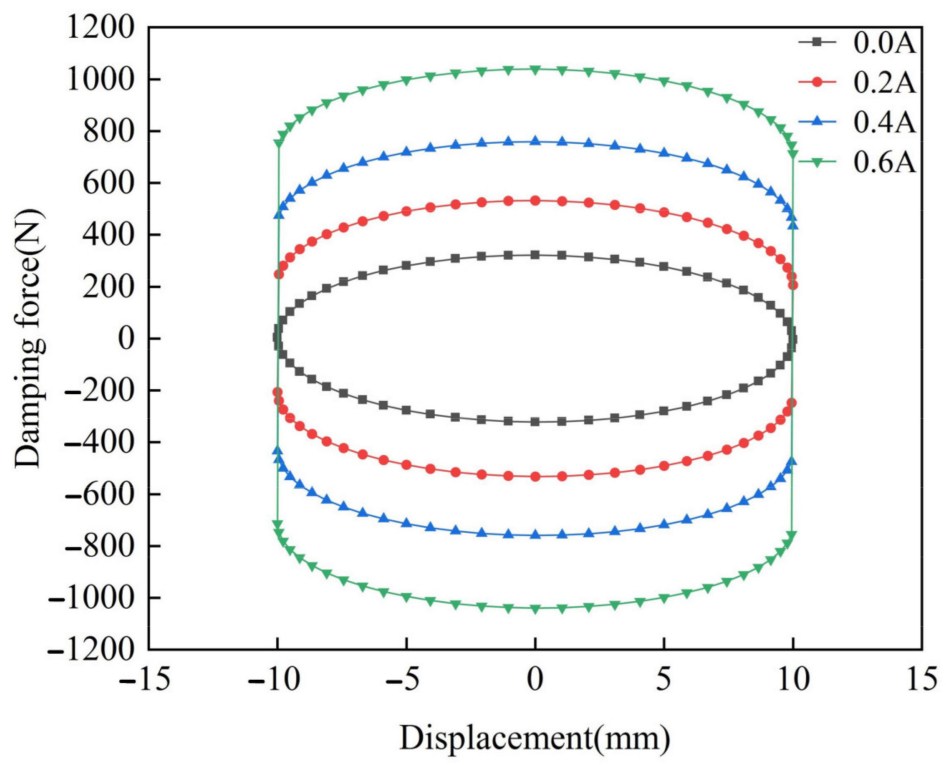

Figure 10. Force-displacement curves under different current simulation conditions.

In order to study the effects of different input excitation conditions on the damping force of the device, the excitation current was kept constant at $0.2 \mathrm{~A}$. The simulation was carried out by setting the sinusoidal excitation at different states, and the results are shown in Figure 11. Figure 11a shows the relationship between the device damping force and displacement for different excitation frequencies at $10 \mathrm{~mm}$ amplitude. Figure $11 \mathrm{~b}$ shows the relationship between the device damping force and displacement for different excitation amplitudes at $1 \mathrm{~Hz}$. From the two figures, it can be seen that the damping force-displacement curves are distributed outwardly from the inside in the shape of "back". The output damping force increases with increases in frequency at the same amplitude. At the same frequency, the output damping force increases with increases in amplitude. As the input excitation at the piston rod increases, the MR fluid flow rate accelerates and the device viscous damping force increases. Since the viscous damping force in the device accounts for a small percentage of the total damping force, the damping force increases a small amount with increasing frequency and amplitude.

To further investigate the relationship between the damping force and the vibration velocity of the self-provided electromagnetic rheostat, we set the conditions for simulation of the relationship under a sinusoidal motion at an amplitude of $10 \mathrm{~mm}$ and a frequency of $1 \mathrm{~Hz}$; the variation in the output damping force versus velocity of the device for different excitation currents is shown in Figure 12.

As can be seen from the figure, the output damping force will increase with increases in excitation current and vibration speed, but the increase with speed is much smaller than that seen with current. This is because the increase in excitation current will cause the magnetically induced damping force of the damper to become larger, and the increase in vibration speed will cause the viscous damping force of the damper to become larger. The viscous damping force is much smaller than the magnetically induced damping force, so the effect of speed on the output damping force is not as obvious as that of current. 


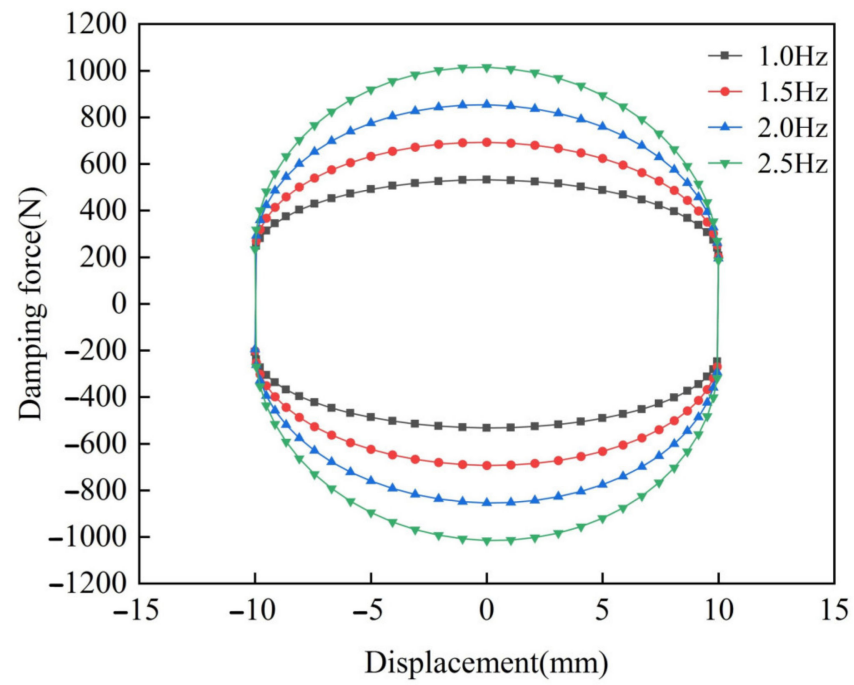

(a)

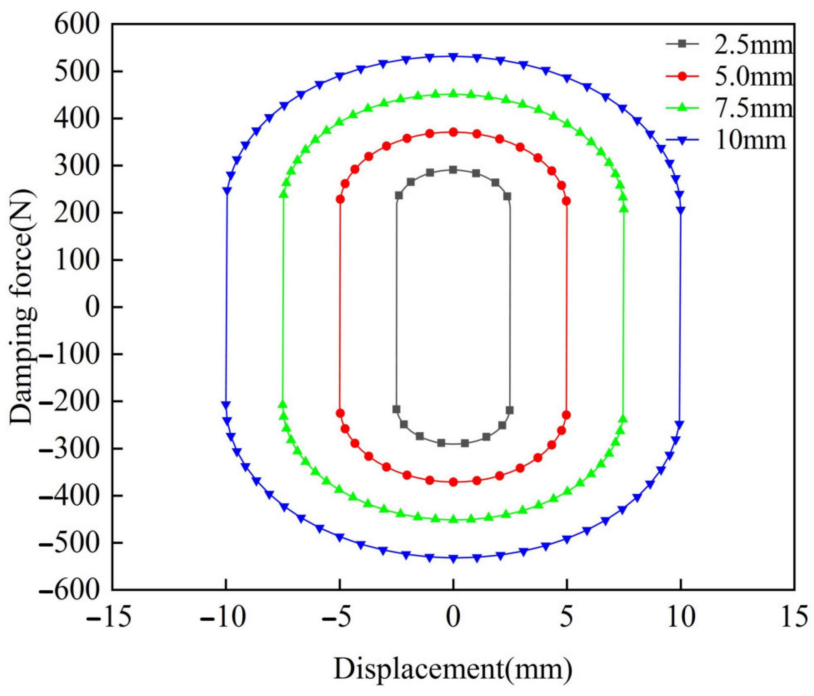

(b)

Figure 11. Force-displacement curves under different sinusoidal excitation simulation conditions. (a) Force-displacement curves under different frequency simulation conditions. (b) Force-displacement curves under different amplitude simulation conditions.

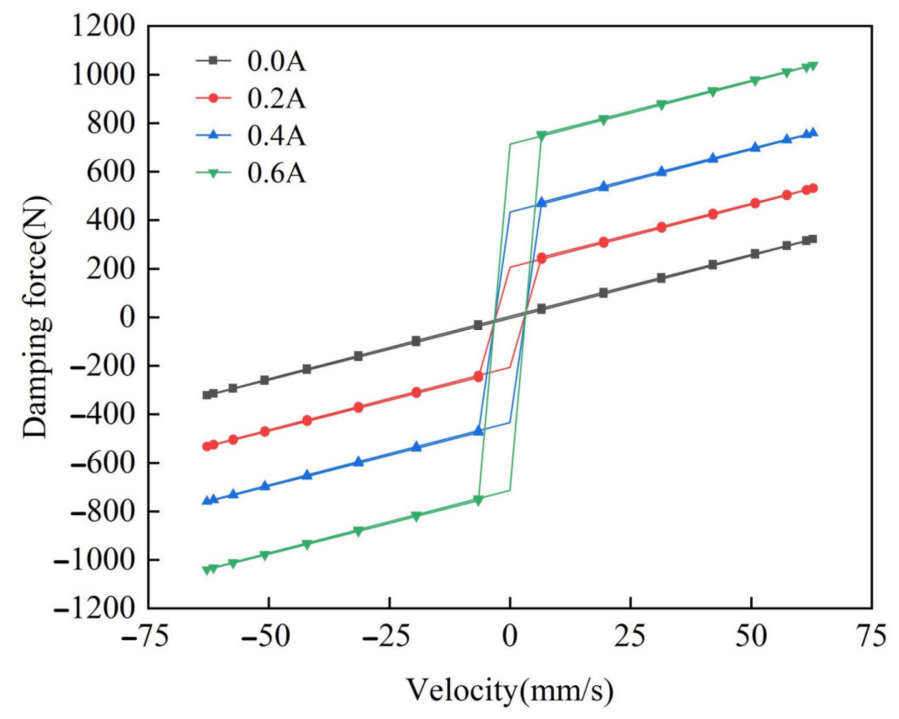

Figure 12. Force velocity curves under different current simulation conditions.

\section{Bench Test of Self-Powered the MR Damper}

The prototype of the self-powered MR damper is shown in Figure 13, and the test device of the new self-powered MR damper bench test is shown in Figure 14. The system mainly consists of a damper excitation table, a proposed MR damper to be tested, a DCregulated power supply, a digital oscilloscope, a controller and a monitor. One end of the MR damper is fixed by the upper clamp to the cross beam of the table before the experiment starts, and the other end is fixed by the lower clamp of the excitation table. The DC-regulated power supply is energized to the coil. The hydraulic fixture on the test bench has a rated dynamic load capacity of $25 \mathrm{kN}$, a working pressure of $21 \mathrm{MPa}$, and an overall height of $131 \mathrm{~mm}$. The electro-hydraulic servo controller is connected to the damper exciter table, which controls the exciter table in order to drive the damper to produce the corresponding vibration. At the same time, the in-built force and speed sensor in the test bench will collect the speed, position, and output damping force of the self-supplied MR 
damper in each working state, and feed back to the computer. At the same time, three external resistor $R=0.8 \Omega$ loads are connected to the three-phase generator in a star shape, the voltage signal output from the generator is recorded by a digital oscilloscope, and the output power of the self-powered MR damper can be obtained by later calculation.

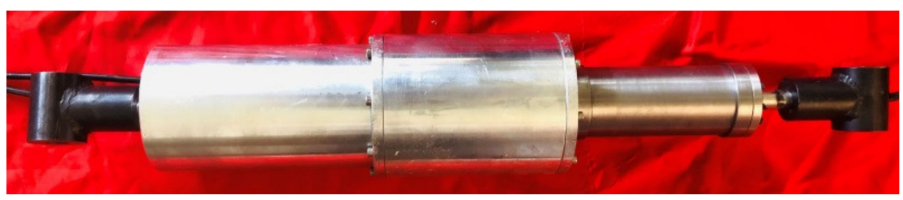

Figure 13. Prototype of self-powered MR damper.

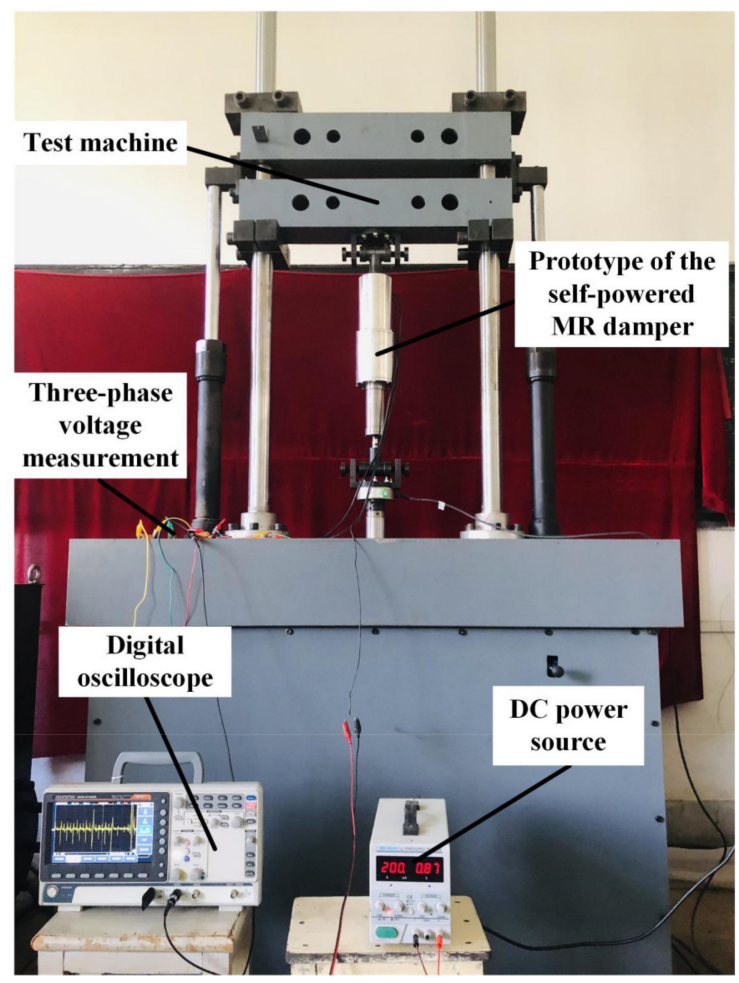

Figure 14. Bench test of self-powered MR damper.

\section{Results and Discussion}

In the experimental tests, the amplitude of the sinusoidal motion was $10 \mathrm{~mm}$, the frequency was $1 \mathrm{~Hz}$, and the output damping force with different currents was measured as shown in Figure 15. When the loading current was $0 \mathrm{~A}$, the maximum damping force output by the damper was $131 \mathrm{~N}$. When the loading current was $0.6 \mathrm{~A}$, the positive damping force output by the damper was $1035 \mathrm{~N}$, and the maximum damping force output in the negative direction reached $1040 \mathrm{~N}$. The damping force output by the damper increased with increases in DC current. Compared with the simulation results, the reverse damping force output by the damper in the experiment was higher than the forward damping force, which is caused by the self-weight of the cylinder and MR fluid of the damper, and the poor sealing between the piston rod and the end cap. For this reason, future work is also needed to reduce the influence of the damper's gravity and choose a better sealing method, to solve the above problems. 


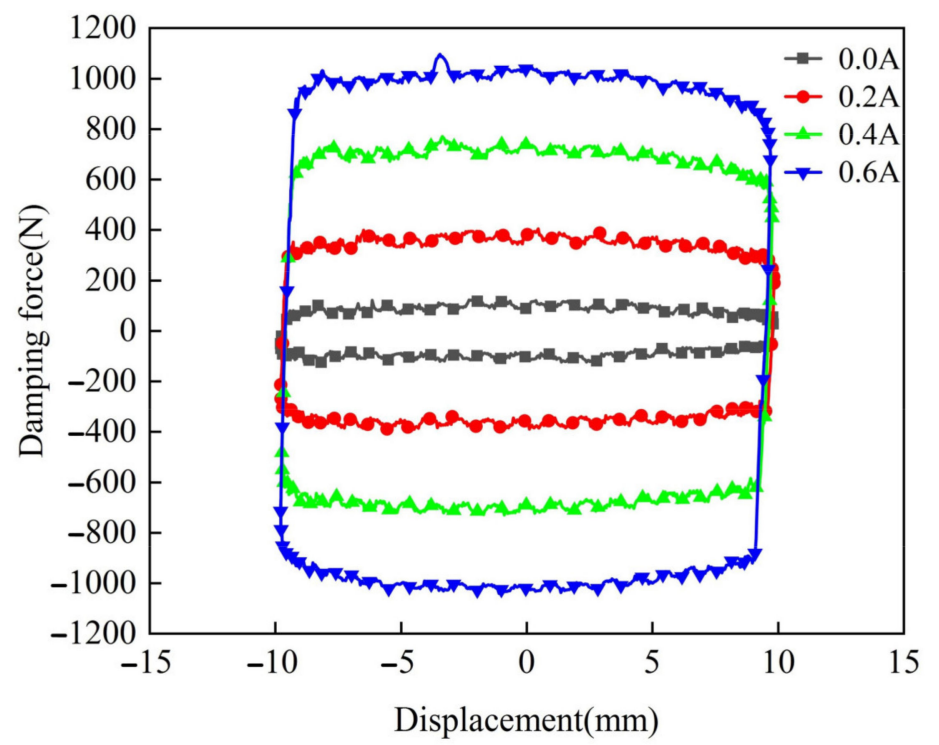

Figure 15. Relationship of force and displacement under different current experimental conditions.

To analyze the effect of input excitation on the damping performance of the selfpowered MR damper, the excitation current was fixed at $0.2 \mathrm{~A}$, and the frequency and amplitude of the sinusoidal motion of the excitation table were changed in turn. The variation of damping force with displacement under different excitation conditions is shown in Figure 16. The damping force-displacement relationship at different frequencies when the amplitude of the experimental condition was $10 \mathrm{~mm}$ is shown in Figure 16a. The damping force-displacement relationship curves at different amplitudes for the experimental condition, setting a frequency of $1 \mathrm{~Hz}$, are shown in Figure 16b. It can be seen from the figure that the damping force output from the damper increased gradually with increases in the loading displacement. This is because when the loading frequency is certain, the viscous damping force of the device becomes larger as the loading displacement increases, and the experimental results are basically consistent with the results of the damping force output from the dampers under the simulation conditions. In addition, the improper sealing method of the piston rod and end cap led to the same displacement amplitude excitation. The damping force output from the damper showed asymmetry for the same compression and tension displacements, but this did not affect the overall pattern of damping force variation with displacement with no current excitation. Therefore, to make the damping performance superior, future work needs to focus on the structural sealing method.

To further investigate the effect of vibration speed on the damping performance of the proposed MR damper, the amplitude of the sinusoidal excitation was set to $10 \mathrm{~mm}$ and the frequency was $1 \mathrm{~Hz}$. The output damping force of the self-powered MR damper with different currents was measured as shown in Figure 17. As can be seen from the figure, the experimental damping force varied with speed in the same way as the simulation results. Although the damping force increased with increments in the vibration velocity, the effect of the applied current on the damping force was much greater than that of vibration velocity on damping force. It shows that the designed damper was not sensitive to the change in vibration velocity, and the damper can output a more stable damping force under different working conditions.

The damping force of the device obtained in the experiment in Figure 17 was basically consistent with the simulated damping force result obtained in Figure 12. Compared with the smoother curve in Figure 12, the fluctuation in the curve in Figure 17 was caused by factors such as the processing error of the device and the installation error of the bench experiment. 


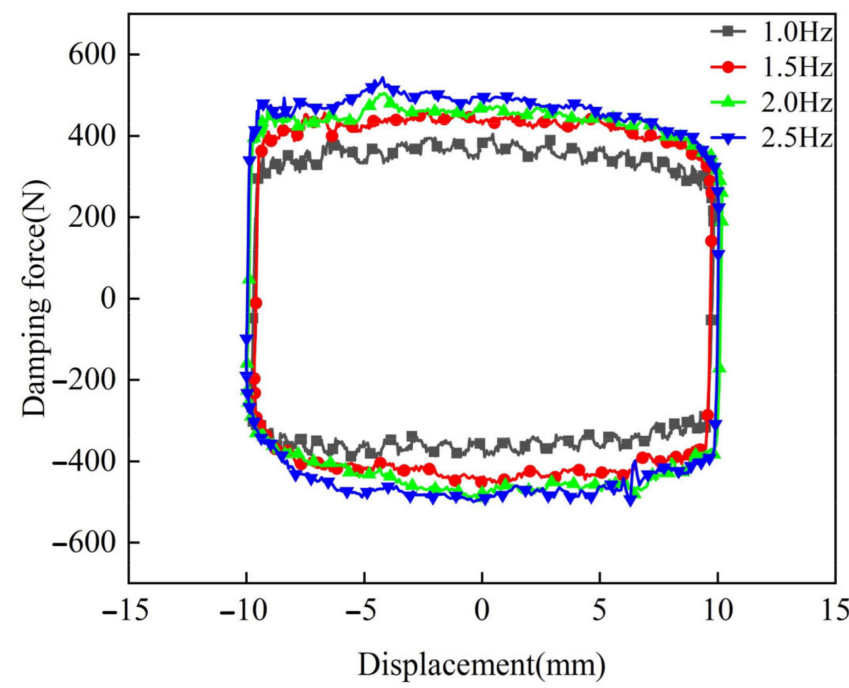

(a)

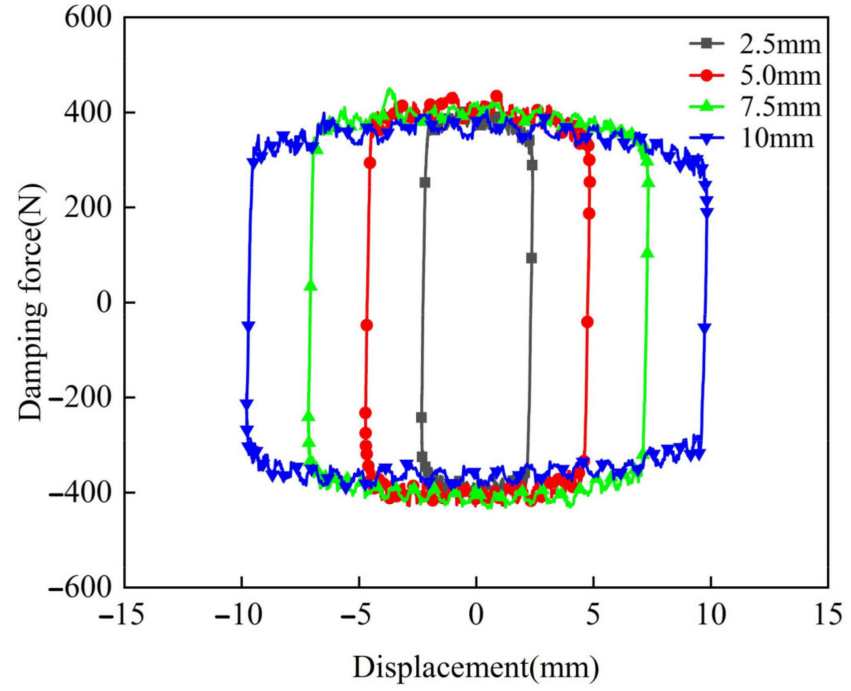

(b)

Figure 16. Relationship of force and displacement under different sinusoidal excitation experimental conditions. (a) Force-displacement curves at different frequency experimental conditions. (b) Force-displacement curves under different amplitude experimental conditions.

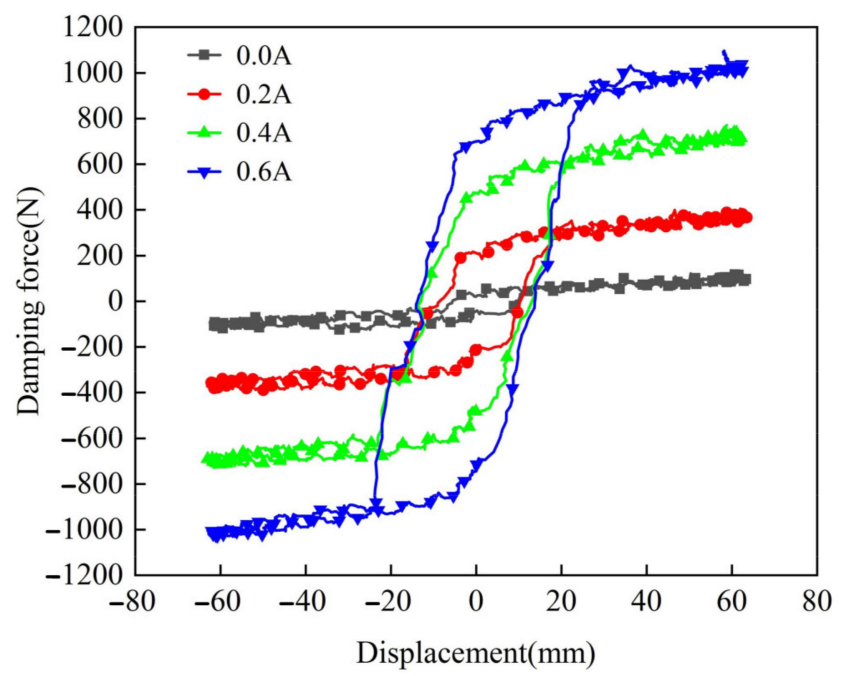

Figure 17. Relationship of force and velocity under different current experimental conditions.

To analyze the vibration energy acquisition performance of the new self-powered MR damper, a prototype of the self-powered MR damper was mounted on a vibration test bench for the vibration energy acquisition test. The amplitude of sinusoidal displacement excitation was set to $5 \mathrm{~mm}, 7.5 \mathrm{~mm}, 10 \mathrm{~mm}$, and $12.5 \mathrm{~mm}$, the frequency was set to $1.5 \mathrm{~Hz}, 2 \mathrm{~Hz}, 2.5 \mathrm{~Hz}$, and $3 \mathrm{~Hz}$, and the voltage signal in each state was saved by a digital oscilloscope. The instantaneous voltage variation curves at different amplitudes and frequencies were obtained as shown in Figure 18. As can be seen from Figure 18, the instantaneous voltage frequency and the excitation frequency remained the same, and the instantaneous voltage increased with increases in the excitation frequency. 


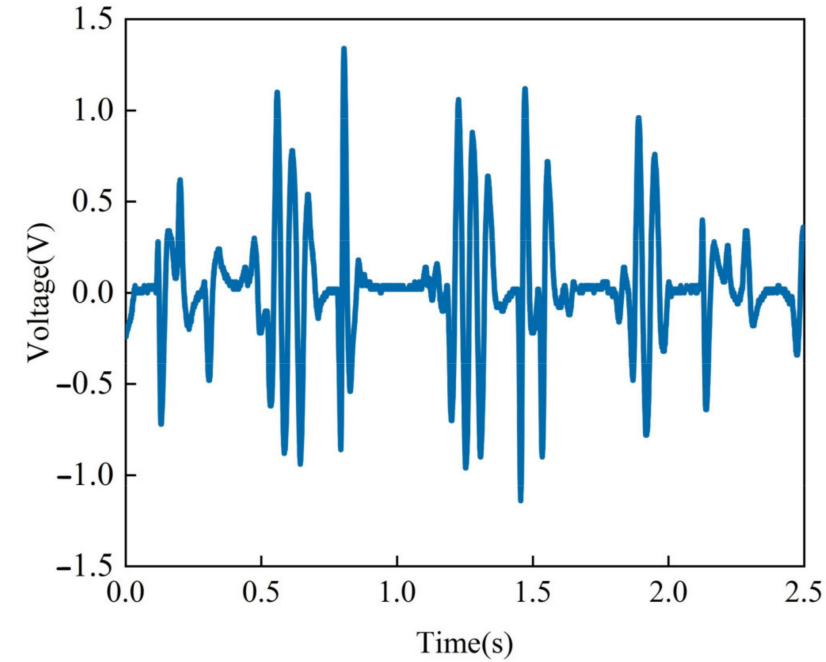

(a)

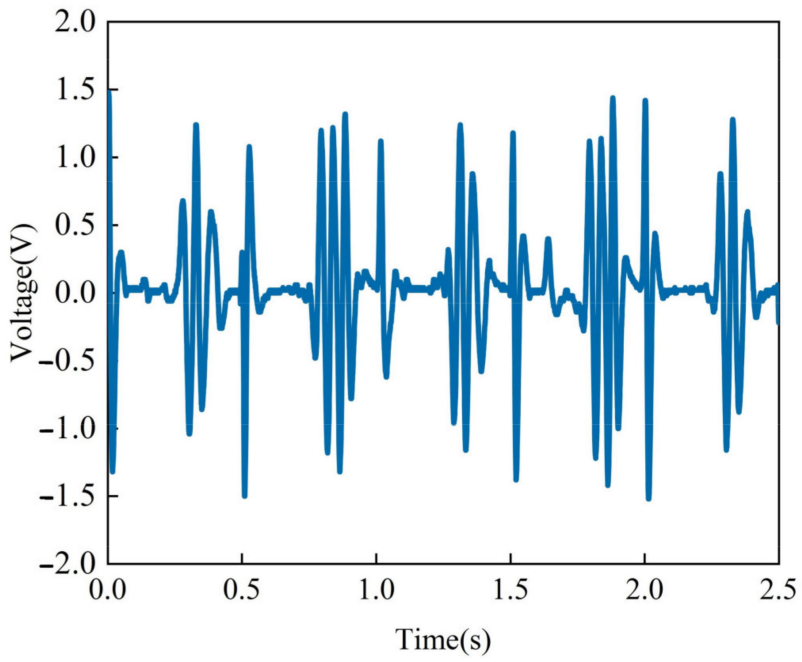

(b)

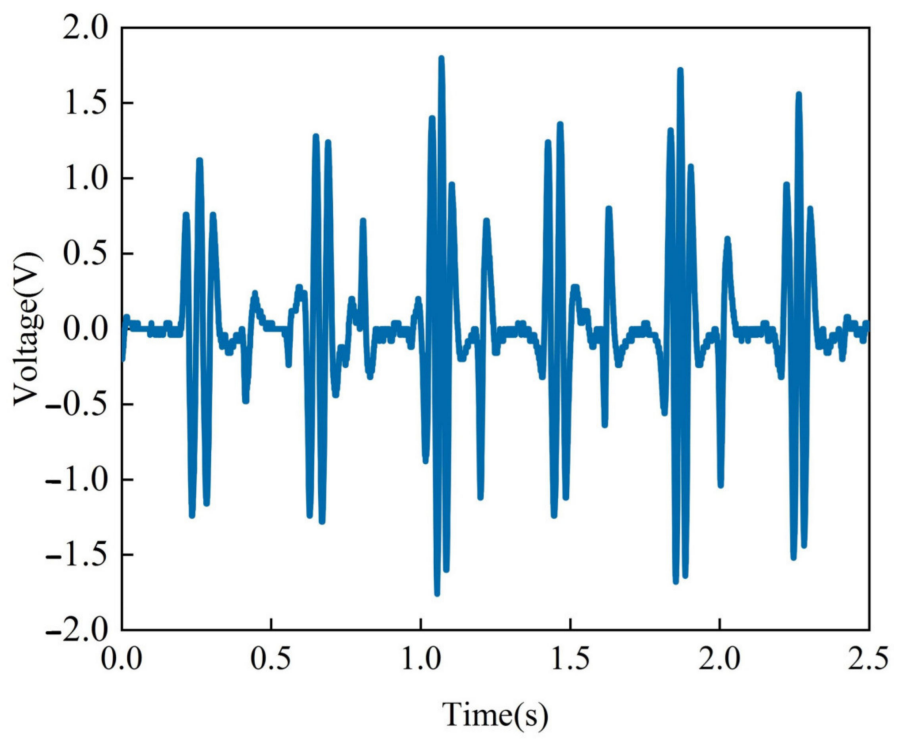

(c)

Figure 18. Instantaneous voltage variation curves at $12.5 \mathrm{~mm}$ amplitude and different frequency experimental conditions.

(a) Frequency of $1.5 \mathrm{~Hz}$. (b) Frequency of $2 \mathrm{~Hz}$. (c) Frequency of $2.5 \mathrm{~Hz}$.

According to variations in the instantaneous voltage, the curve of the instantaneous voltage amplitude with frequency at different amplitudes was established as shown in Figure 19. When the excitation frequency was fixed, the instantaneous voltage amplitude of the device increased with increases in excitation amplitude. When the excitation amplitude was fixed, the instantaneous voltage amplitude of the device increased with increases in excitation frequency.

The instantaneous power of each external resistance is calculated as:

$$
P_{\text {instant }}=\frac{V^{2}}{R}
$$

where $V$ is the instantaneous voltage of a single external resistor. Thus, the average output power of three external resistors of the same value is regarded as:

$$
P_{\text {output(ave) }}=3 \times \frac{\int_{0}^{T} P_{\text {instant }} d t}{T}
$$


Figure 20a,b show the instantaneous voltage and optimal electrical power of a single external resistor at an amplitude of $12.5 \mathrm{~mm}$ and frequency of $3 \mathrm{~Hz}$, respectively. The instantaneous voltage amplitude of the new self-powered MR damper was $1.782 \mathrm{~V}$ and the peak phase power was $4.428 \mathrm{~W}$.

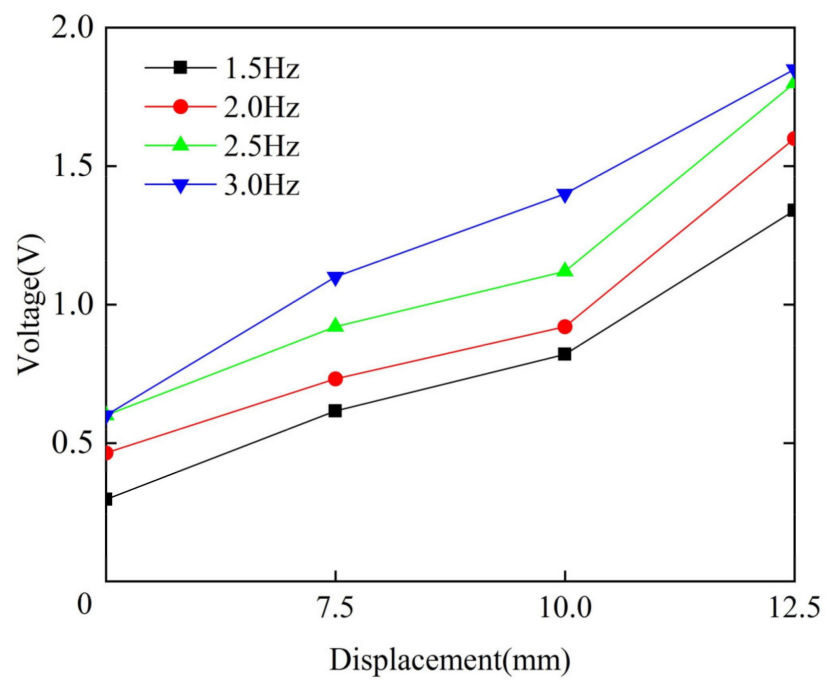

Figure 19. Variation of instantaneous voltage amplitude with frequency under different amplitudes.

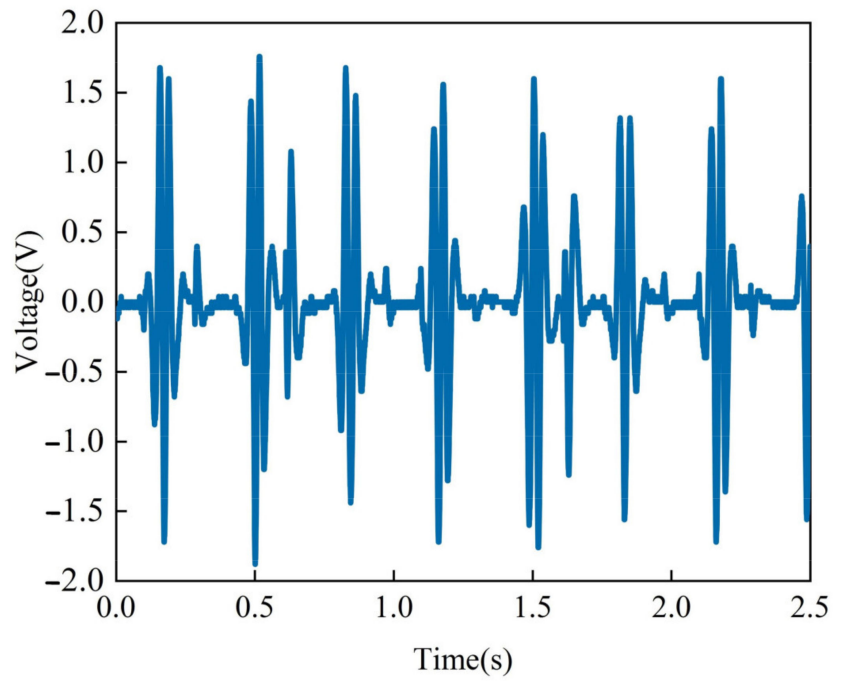

(a)

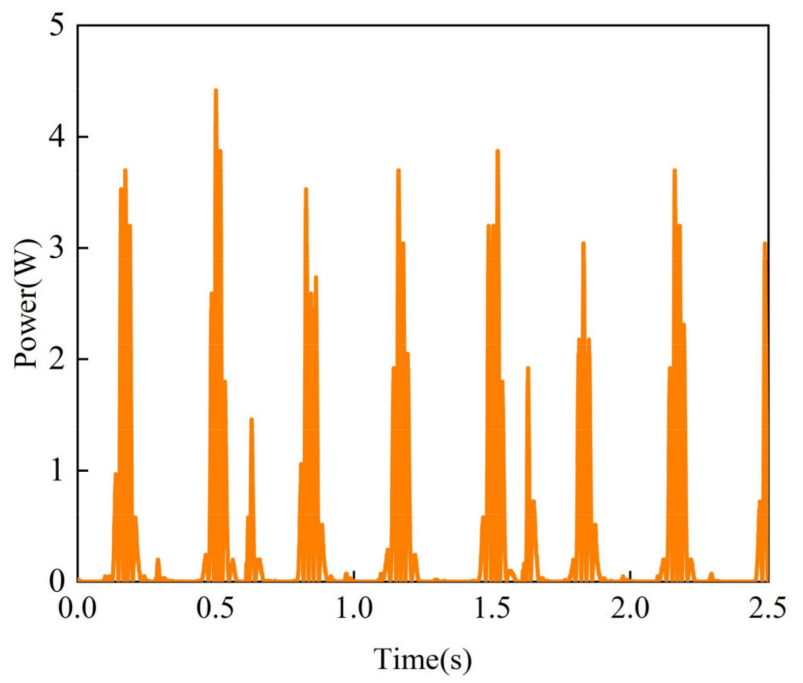

(b)

Figure 20. Damper output waveform at $3 \mathrm{~Hz}$ frequency and $12.5 \mathrm{~mm}$ amplitude connected to a $0.8 \Omega$ external resistor. (a) Voltage waveform. (b) Instantaneous power diagram.

In summary, to increase the performance of the self-powered MR damper vibration energy harvesting, we can increase the transmission ratio of the planetary gearbox between the double-linkage mechanism and the three-phase DC brushless generator. By increasing the ratio of the planetary gearbox, the rotational motion transmitted by the double-linkage mechanism can be further amplified. Under the same input excitation amplitude and frequency, it can make the motor output more instantaneous voltage. However, the addition of a larger ratio planetary gearbox also increases the axial size and mass of the vibration energy-harvesting device, making it difficult to install a self-powered MR damper in a system with limited volume, limiting the scope of application for the damper. Therefore, when designing vibration energy-harvesting devices, we need to consider the size of the 
collected power and its application, such as structure size, device quality, installation space, etc.

\section{Conclusions}

This article analyzed the current research status of different types of dampers by expounding the related technical application fields of MR dampers. According to the structural mode of the shear valve MR damper and the law of electromagnetic induction, a new self-powered MR damper with integrated vibration energy harvesting and damping was proposed and designed. The mathematical models of mechanical calculation and vibration energy collection were deduced, and a kinematics analysis of the double-linkage mechanism was also carried out. The static magnetic field was simulated and analyzed using finite element software, and the corresponding dynamic performance was tested and verified on the built experimental platform.

By combining the damping controllability and energy harvesting capability of MR dampers, the proposed MR dampers not only have good dynamic damping performance but also have energy-harvesting capability. The device is suitable for remote mountainous areas and other temporary emergency situations, greatly expands the application scenarios of MR dampers, and proposes a more effective, new, self-powered MR damper scheme. The structural size and manufacturing cost of the self-powered MR damper are also significantly reduced compared to MR damper systems installed with external self-awareness and energy-harvesting devices. The results show that the damping force increases with increases in control current, input excitation frequency, and amplitude. At an excitation current of $0.6 \mathrm{~A}$, the maximum damping force reaches $1040 \mathrm{~N}$, demonstrating the superiority of this damper for attenuating external vibrations. When the input excitation amplitude is $12.5 \mathrm{~mm}$ and the frequency is $3 \mathrm{~Hz}$, the instantaneous voltage amplitude of the MR damper is $1.782 \mathrm{~V}$, and the peak phase power is $4.428 \mathrm{~W}$. The new MR damper has the advantages of compact structure, small installation size, and high efficiency of vibration energy harvesting.

Author Contributions: L.L. developed the self-powered MR damper and wrote the draft; G.H. contributed the idea and edited the paper; L.Y. carried out theoretical analysis; H.Q. supported the experimental process. All authors have read and agreed to the published version of the manuscript.

Funding: This research was funded by the National Natural Science Foundation of China, grant numbers 52165004 and 51765016.

Institutional Review Board Statement: Not applicable.

Informed Consent Statement: Not applicable.

Data Availability Statement: Not applicable.

Conflicts of Interest: The authors declare no conflict of interest.

\section{References}

1. Bai, X.; Hu, W.; Wereley, N.M. Magnetorheological damper utilizing an inner bypass for ground vehicle suspensions. IEEE Trans. Magn. 2013, 4, 3422-3425. [CrossRef]

2. Ding, R.; Wang, R.; Meng, X.; Chen, L. Energy consumption sensitivity analysis and energy-reduction control of hybrid electromagnetic active suspension. Mech. Syst. Signal Process. 2019, 134, 106301. [CrossRef]

3. Zhang, Y.; Chen, H.; Guo, K.; Zhang, X.; Li, S.E. Electro-hydraulic damper for energy harvesting suspension: Modeling, prototyping and experimental validation. Appl. Energy 2017, 199, 1-12. [CrossRef]

4. Sahu, G.N.; Singh, S.; Singh, A.; Law, M. Static and dynamic characterization and control of a high-performance electro-hydraulic actuator. Actuators 2020, 9, 46. [CrossRef]

5. Ning, D.; Sun, S.; Du, H.; Li, W.; Zhang, N. Vibration control of an energy regenerative seat suspension with variable external resistance. Mech. Syst. Signal Process. 2018, 106, 94-113. [CrossRef]

6. Zhu, S.; Shen, W.-A.; Xu, Y.-L. Linear electromagnetic devices for vibration damping and energy harvesting: Modeling and testing. Eng. Struct. 2012, 34, 198-212. [CrossRef]

7. Jamshidi, M.; Chang, C.C.; Bakhshi, A. Design and control of a self-powered hybrid electromagnetic damper. J. Sound Vib. 2018, 428, 147-167. [CrossRef] 
8. Sun, S.S.; Tang, X.; Yang, J.; Ning, D.; Du, H. A new generation of magnetorheological vehicle suspension system with tunable stiffness and damping characteristics. IEEE Trans. Ind. Inform. 2019, 15, 4696-4708. [CrossRef]

9. Yang, B.; Sun, S.; Deng, L.; Jin, T.; Li, W.; Li, H. Vibration control of a tunnel boring machine using adaptive magnetorheological damper. Smart Mater. Struct. 2019, 28, 115012. [CrossRef]

10. Yang, J.; Ning, D.; Sun, S.; Zheng, J.; Lu, H.; Nakano, M.; Zhang, S.; Du, H.; Li, W. A semi-active suspension using a magnetorheological damper with nonlinear negative-stiffness component. Mech. Syst. Signal Pract. 2021, 147, 107071-107091. [CrossRef]

11. Sapiński, B.; Orkisz, P. Real-time sensing action of the electromagnetic vibration-based energy harvester for a magnetorheological damper control. Energies 2021, 14, 2845. [CrossRef]

12. Wang, R.; Gu, F.; Cattley, R.; Ball, A.D. Modelling, testing and analysis of a regenerative hydraulic shock absorber system. Energies 2016, 9, 386. [CrossRef]

13. Zhang, Y.; Guo, K.; Wang, D.; Chen, C.; Li, X. Energy conversion mechanism and regenerative potential of vehicle suspensions. Energy 2017, 119, 961-970. [CrossRef]

14. Lin, X.; Xuexun, G. Hydraulic transmission electromagnetic energy-regenerative active suspension and its working principle. In Proceedings of the 2010 2nd International Workshop on Intelligent Systems and Applications (ISA 2010), Wuhan, China, 22-23 May 2010.

15. Sabzehgar, R.; Maravandi, A.; Moallem, M. Energy regenerative suspension using an algebraic screw linkage mechanism. IEEE/ASME Trans. Mechatron. 2014, 19, 1251-1259. [CrossRef]

16. Zhang, Y.; Huang, K.; Yu, F.; Gu, Y.; Li, D. Experimental verification of energy-regenerative feasibility for an automotive electrical suspension system. In Proceedings of the 2007 IEEE International Conference on Vehicular Electronics and Safety (ICVES), Beijing, China, 13-15 December 2007.

17. Salman, W.; Qi, L.; Zhu, X.; Pan, H.; Zhang, X.; Bano, S.; Zhang, Z.; Yuan, Y. A high-efficiency energy regenerative shock absorber using helical gears for powering low-wattage electrical device of electric vehicles. Energy 2018, 159, 361-372. [CrossRef]

18. Zhao, Q.; Yuan, J.; Jiang, H.; Yao, H.; Wen, B. Vibration control of a rotor system by shear thickening fluid dampers. J. Sound Vib. 2021, 494, 115883. [CrossRef]

19. Kim, W.H.; Park, J.H.; Kaluvan, S.; Lee, Y.S.; Choi, S.B. A novel type of tunable magnetorheological dampers operated by permanent magnets. Sens. Actuators A Phys. 2017, 255, 104-117. [CrossRef]

20. Moghadam, M.G.E.; Shahmardan, M.M.; Norouzi, M. Dissipative particle dynamics modeling of a mini-MR damper focus on magnetic fluid. J. Mol. Liq. 2019, 283, 736-747. [CrossRef]

21. Du, C.; Zeng, F.; Liu, B.; Fu, Y. A novel magnetorheological fluid damper with a heat insulation function. Smart Mater. Struct. 2021, 30, 075001. [CrossRef]

22. Yazid, I.I.M.; Mazlan, S.A.; Kikuchi, T.; Zamzuri, H.; Imaduddin, F. Design of magnetorheological damper with a combination of shear and squeeze modes. Mater. Des. 2014, 54, 87-95. [CrossRef]

23. Robinson, R.; Hu, W.; Wereley, N.M. Linking porosity and tortuosity to the performance of a magneto-rheological damper employing a valve filled with porous media. IEEE Trans. Magn. 2010, 46, 2156-2159. [CrossRef]

24. Kim, K.; Chen, Z.; Yu, D.; Rim, C. Design and experiments of a novel magneto-rheological damper featuring bifold flow mode. Smart Mater. Struct. 2016, 25, 1-10. [CrossRef]

25. Or, S.W.; Duan, Y.F.; Ni, Y.Q.; Chen, Z.H.; Lam, K.H. Development of magnetorheological dampers with embedded piezoelectric force sensors for structural vibration control. J. Intell. Mater. Syst. Struct. 2008, 19, 1327-1338. [CrossRef]

26. Lam, K.H.; Chen, Z.H.; Ni, Y.Q.; Chan, H.L.W. A magnetorheological damper capable of force and displacement sensing. Sens. Actuators A Phys. 2010, 158, 51-59. [CrossRef]

27. Hu, G.; Zhou, W.; Li, W. A new magnetorheological damper with improved displacement differential self-induced ability. Smart Mater. Struct. 2015, 24, 87001. [CrossRef]

28. Dong, X. Design and characterization of axial flux permanent magnet energy harvester for vehicle magnetorheological damper. Smart Mater. Struct. 2015, 25, 15024. [CrossRef]

29. Sapiński, B. Energy-harvesting linear MR damper: Prototyping and testing. Smart Mater. Struct. 2014, 23, 035021. [CrossRef]

30. Xinchun, G.; Yonghu, H.; Yi, R.; Hui, L.; Jinping, O. A novel self-powered MR damper: Theoretical and experimental analysis. Smart Mater. Struct. 2015, 24, 105033. [CrossRef]

31. Yu, M.; Peng, Y.; Wang, S.; Fu, J.; Choi, S.B. A new energy-harvesting device system for wireless sensors, adaptable to on-site monitoring of MR damper motion. Smart Mater. Struct. 2014, 23, 077022. [CrossRef] 